\title{
Differences in taste between three polyethylene glycol preparations: a randomized double-blind study
}

This article was published in the following Dove Press journal:

Patient Preference and Adherence

16 August 2011

Number of times this article has been viewed

\author{
Tze J Lam \\ Chris J Mulder \\ Richelle JF Felt-Bersma \\ Department of Gastroenterology \\ and Hepatology, VU University \\ Medical Center, Amsterdam, \\ the Netherlands
}

Correspondence: Tze J Lam VU University Medical Center, Department of Gastroenterology and Hepatology, PO Box 7057, 1007 MB Amsterdam, the Netherlands $\mathrm{Tel}+3$ I 204446013

Fax +3। 204440554

Email tj.lam@vumc.nl
Background and aim: Patients suffering from chronic constipation require long-term, regular therapy with laxatives. Literature regarding patient preference and acceptance in polyethylene glycol preparations is scarce. Therefore, this research aimed to identify preference between the three polyethylene glycol 3350, namely Molaxole $^{\circledR}$, Movicol $^{\circledR}$, and Laxtra Orange ${ }^{\circledR}$. Furthermore, taste is one of the most important factors leading to patients' adherence, particularly when the treatment lasts for a long time.

Methods: In this randomized, cross-over double-blind study, 100 volunteers were recruited by advertisement. The volunteers were invited to taste the preparations and grade the taste using a five-point hedonic scale (extremely poor taste [1] to extremely good taste [5]). The volunteers were then asked to choose the most palatable preparation.

Results: One hundred volunteers with a mean age of 35 years (range 20-61) were randomized (76 females). Molaxole ${ }^{\circledR}$, Movicol $^{\circledR}$, and Laxtra Orange ${ }^{\circledR}$ had a mean hedonic score of 2.76 (SD: 0.82 ), 2.81 (SD: 0.76) and 3.12 (SD: 0.82) respectively. The hedonic taste score for Laxtra Orange $^{\circledR}$ was significantly better than Molaxole $^{\circledR}(P=0.001)$ and Movicol $^{\circledR}(P=0.001)$. No difference was found between Molaxole $^{\circledR}$ and Movicol $^{\mathbb{B}}(P=0.61)$. Molaxole $^{\circledR}$ was the most preferred preparation for 19 volunteers $(19 \%)$ Movicol $^{\circledR}$ for 24 volunteers $(25 \%)$ and Laxtra Orange $^{\circledR}$ for 55 volunteers $(56 \%)$. Two volunteers had no preference. The order in which volunteers tested the preparations had no influence on the taste results. No significant differences in age or gender were observed.

Conclusion: Laxtra Orange ${ }^{\circledR}$ was most palatable preparation. This may have implications for adherence in patients with chronic constipation.

Keywords: constipation, polyethylene glycol, laxative, macrogol, molaxole, movicol, laxtra, medication adherence

\section{Introduction}

Chronic idiopathic constipation is a frequently reported medical disorder and reduces patients' quality of life. ${ }^{1}$ The estimated prevalence in Europe is $17 \%$ and increases with age, especially in those over the age of 65 years. ${ }^{2,3}$

The initial management of chronic idiopathic constipation includes behavior modification and dietary changes. ${ }^{4}$ For patients who do not respond to this management, laxatives present an alternative therapy. ${ }^{1} \mathrm{Up}$ to $40 \%$ of these patients use laxatives. ${ }^{5}$

A variety of laxatives are available for treating constipation: bulk forming, osmotic, and stimulant laxatives. Osmotic laxatives, particularly polyethylene glycol (PEG) preparations are trendsetting in the constipation market. PEG preparations are relatively 
safe, inexpensive, widely used, and are even better than lactulose in improving stool frequency and consistency. ${ }^{6-8}$

Although these modalities may benefit some patients with temporary constipation, most of the patients often need to use these compounds on a regular basis. According to the literature, only $50 \%$ of patients who suffer from chronic diseases adhere to treatment recommendations, which results in suboptimal outcomes. ${ }^{9,10}$ There are numerous factors that affect adherence, including characteristics of the illness, interaction between physician and patient, the complexity and duration of treatment, side effects of treatment, and cost of treatment. ${ }^{11}$ Furthermore, medication palatability is also crucial for adherence. Several studies have addressed the palatability of medication for different disorders, including hypertension, HIV, and Alzheimer's disease. ${ }^{12-14}$ Pharmaceutical companies have tried to improve palatability by adding flavors, such as vanilla, strawberry, and citrus, although this is primarily in medication for children. ${ }^{15-17}$

Literature regarding patient preference and acceptance in PEG preparations is scarce. ${ }^{18-20}$ Therefore, we aimed to compare three commonly used PEG 3350 preparations, Molaxole $^{\circledR}$, Movicol $^{\circledR}$, and Laxtra Orange ${ }^{\circledR}$ in taste and to evaluate preference.

\section{Patients and methods}

A total of 100 volunteers recruited by advertising through posters were included in a cross-over, double-blind, randomized study.

Volunteers were presented with three preparations of $25 \mathrm{~mL}$ in a randomized order. After tasting each sample without swallowing, volunteers rinsed their mouths with water. The samples were graded using a five-point hedonic scale (extremely poor taste [1] to extremely good taste [5]). Following this, volunteers were asked to choose the most palatable preparation.

This was an investigator initiated study that was approved by the Ethics Committee of VU Medical Center, Amsterdam, the Netherlands, and was in accordance with the Helsinki Declaration. All patients gave informed consent prior to participation.

\section{Polyethylene glycol preparations}

Three PEG 3350 preparations, Molaxole ${ }^{\circledR}$, Movicol $^{\circledR}$, and Laxtra Orange ${ }^{\circledR}$ were chosen as these are the most commonly prescribed product variants. All three PEG 3350 preparations contain similar doses of macrogol, electrolytes and sweetener, namely $3.125 \mathrm{~g}$ macrogol $3350,350.7 \mathrm{mg}$ sodium chloride, $178.5 \mathrm{mg}$ sodium hydroxide carbonate, $46.6 \mathrm{mg}$ potassium chloride and acesulfame K (E950). Molaxole additionally contains lemon flavor, Movicol $^{\circledR}$ a lime/lemon flavor and Laxtra Orange ${ }^{\circledR}$ an orange flavor.

\section{Statistical analyses}

Data analysis was performed using the statistical software SPSS (v 15.0; SPSS, Inc, Chicago, IL). Results were described as means and proportions. The Wilcoxon signedrank test was used to determine the difference in taste between the preparations. A $P$-value of less than 0.05 was considered statistically significant. When using a Bonferroni correction for three interdependent classes, a $P$-value less than $\alpha / 3=0.01667$ was considered statistically significant.

\section{Results}

One-hundred volunteers were randomized (mean age: 35 years [range: 20-61], 76 female). The mean hedonic score was 2.76 (SD: 0.82), 2.81 (SD: 0.76) and 3.12 (SD: 0.82) for Molaxole ${ }^{\circledR}$, Movicol $^{\circledR}$, and Laxtra Orange ${ }^{\circledR}$ respectively (Figure 1). The hedonic taste score for Laxtra Orange ${ }^{\circledR}$ was significantly higher than Molaxole $^{\circledR}(P=0.001)$ and Movicol $^{\circledR}(P=0.001)$. No significant difference was found between Molaxole ${ }^{\circledR}$ and Movicol $^{\circledR}$ $(P=0.61)$. One volunteer graded all three preparations 1 , whereas one volunteer graded all preparations 5 (Figure 1).

The order in which volunteers tested the preparations had no influence on the taste results. Thirty-eight (39\%), 24 (24\%), and 36 volunteers (37\%) found the first, second,

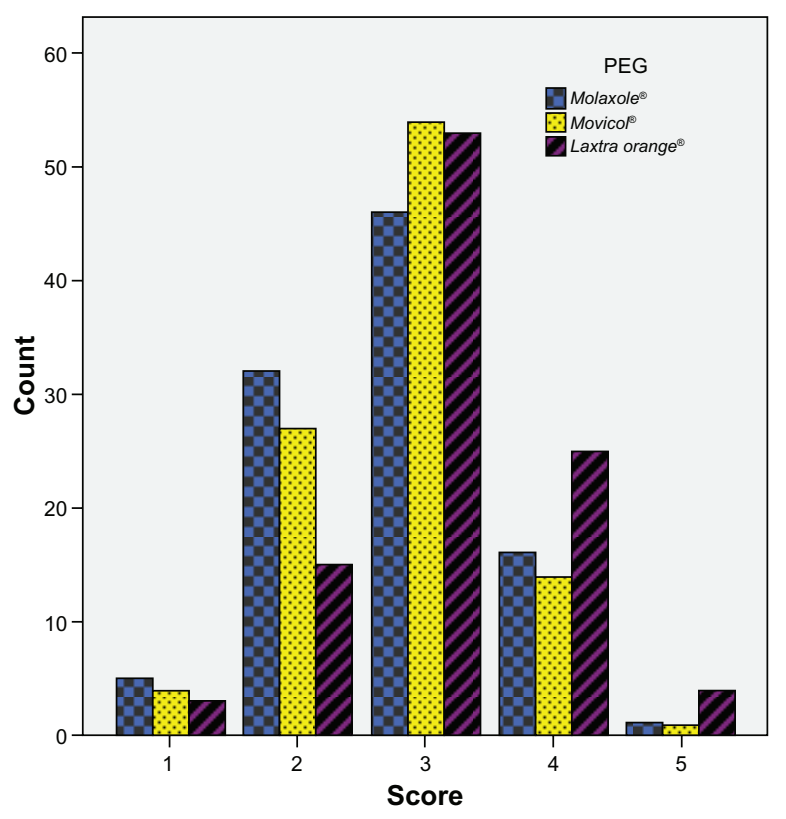

Figure I Hedonic taste score for all polyethylene glycol preparations (PEG) ( $I$ = extremely poor taste, 5 = extremely good taste); the mean hedonic score was 2.76 (SD: 0.82), 2.8I (SD: 0.76) and 3.12 (SD: 0.82) for Molaxole ${ }^{\circledR}$, Movicol $^{\circledR}$, and Laxtra Orange ${ }^{\circledast}$, respectively. 
and third tested preparation respectively most palatable. After decoding, Molaxole ${ }^{\circledR}$ was the most liked preparation in 19 volunteers $(19 \%)$, Movicol ${ }^{\circledR}$ in 24 volunteers $(25 \%)$, and Laxtra Orange ${ }^{\circledR}$ in 55 volunteers (56\%) (Figure 2). Two volunteers had no preference.

There were no significant differences in age or gender observed.

\section{Discussion}

Nonadherence to treatment is a problem of increasing concern. Many patients experience difficulty with taking medication because of aversion to the taste, which results in suboptimal adherence. Although there are no easy solutions to this dilemma, pharmaceutical companies have tried to improve palatability by adding flavors to medications, such as vanilla, strawberry, and citrus. ${ }^{15-17}$

This randomized, double-blind study, which involved 100 volunteers, showed that the orange flavor of Laxtra Orange ${ }^{\circledR}$ was significantly better tasting than the lemon flavor of Molaxole ${ }^{\circledR}$, and the lime and lemon flavor of Movicol $^{\circledR}$. No difference was found between Molaxole ${ }^{\circledR}$ and Movicol $^{\circledR}$. No differences between gender, age, or sequence of tasting were found.

PEG preparation with electrolytes is mixed with water. A good suggestion is to mix the PEG preparation with cold water, which makes it more palatable. Since all these PEG preparations contain electrolytes, it cannot be mixed with juice, coffee, or tea. However, recent studies showed that a PEG preparation without electrolytes is as effective and safe as a PEG preparation with electrolytes in the treatment of constipation in elderly patients and children. ${ }^{21,22}$

\section{Limitations}

There are some limitations in our study that need to be considered. The volunteers were only offered a small sip

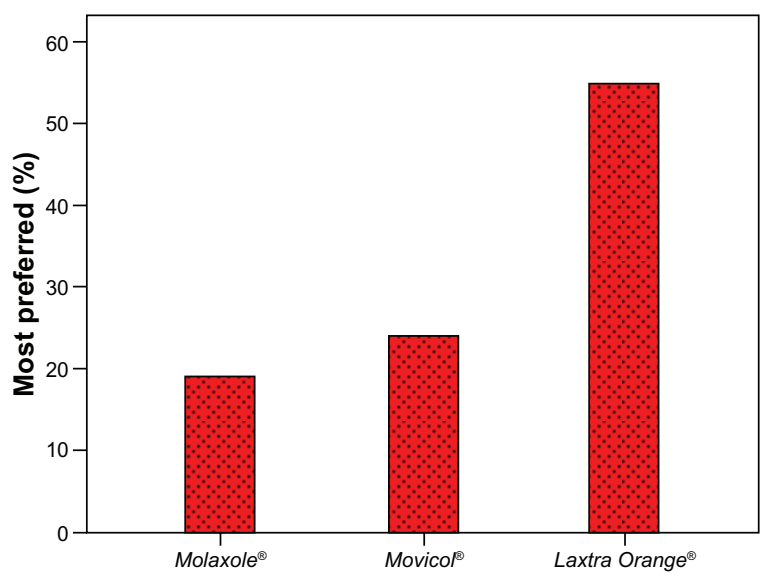

Figure 2 Most preferred preparation in 100 volunteers. of each preparation, whereas in the real-world situation, a patient with constipation may need to ingest more than $125 \mathrm{~mL}$ of the medication. Therefore, we cannot be sure that the preference is still valid for larger quantities. However, since a more palatable medication can improve adherence, ${ }^{10}$ it might be worthwhile to consider Laxtra Orange $e^{\circledR}$ if patient has complaints regarding the taste.

In addition, we acknowledge that the volunteers were relatively young, and therefore our results may not be representative for the whole constipated population. Constipation disproportionately affects older adults and it is well recognized that older adults have less sensitivity in their taste acuity. ${ }^{23}$ However, no apparent effect of age was found.

\section{Conclusion}

In conclusion, we found that Laxtra Orange ${ }^{\circledR}$ was the most favored preparation in a single test. Given the fact that the three tested preparations have a similar PEG and electrolyte content and therefore the same efficacy, for complaints about the taste, switching to Laxtra Orange ${ }^{\circledR}$ could improve the adherence of the patient.

\section{Acknowledgment/disclosure}

This study was sponsored financially by Tramedico BV, Weesp, the Netherlands, manufacturers of Laxtra. However, the authors have no other conflicts of interest relevant to the content of this manuscript. Tramedico BV did not play any role in the design and conduct of the study. In particular, Tramedico BV had no input into the review of the results and writing of this manuscript.

\section{References}

1. Rao SS, Go JT. Update on the management of constipation in the elderly: new treatment options. Clin Interv Aging. 2010;5:163-171.

2. Chatoor D, Emmnauel A. Constipation and evacuation disorders. Best Pract Res Clin Gastroenterol. 2009;23:517-530.

3. Peppas G, Alexiou VG, Mourtzoukou E, Falagas ME. Epidemiology of constipation in Europe and Oceania: a systematic review. $B M C$ Gastroenterol. 2008;8:5.

4. Camilleri M, Bharucha AE. Behavioural and new pharmacological treatments for constipation: getting the balance right. Gut. 2010;59: 1288-1296.

5. Wald A, Scarpignato C, Mueller-Lissner S, et al. A multinational survey of prevalence and patterns of laxative use among adults with self-defined constipation. Aliment Pharmacol Ther. 2008;28:917-930.

6. Taylor RR, Guest JF. The cost-effectiveness of macrogol 3350 compared to lactulose in the treatment of adults suffering from chronic constipation in the UK. Aliment Pharmacol Ther. 2010;31:302-312.

7. Lee-Robichaud H, Thomas K, Morgan J, Nelson RL. Lactulose versus Polyethylene Glycol for Chronic Constipation. Cochrane Database Syst Rev. 2010;7:CD007570.

8. Belsey JD, Geraint M, Dixon TA. Systematic review and meta analysis: polyethylene glycol in adults with non-organic constipation. Int J Clin Pract. 2010;64:944-955. 
9. World Health Organisation. Adherence to long term therapies: evidence for action. Geneva, Switzerland: World Health Organisation; 2003.

10. Osterberg L, Blaschke T. Adherence to medication. $N$ Engl J Med. 2005;353:487-497.

11. Ingersoll KS, Cohen J. The impact of medication regimen factors on adherence to chronic treatment: a review of literature. J Behav Med. 2008;31:213-224.

12. Van der Linden D, Callens S, Brichard B, Colebunders R. Pediatric HIV: new opportunities to treat children. Expert Opin Pharmacother. 2009;10:1783-1791.

13. Meier CM, Simonetti GD, Ghiglia S, et al. Palatability of angiotensin II antagonists among nephropathic children. Br J Clin Pharmacol. 2007;63:628-631.

14. Yan YD, Woo JS, Kang JH, Yong CS, Choi HG. Preparation and evaluation of taste-masked donepezil hydrochloride orally disintegrating tablets. Biol Pharm Bull. 2010;33:1364-1370.

15. Ishizaka T, Okada S, Tokuyama E, Mukai J, Uchida T. Suppression of bitterness and improvement of palatability of commercial prednisolone powder. Chem Pharm Bull (Tokyo). 2008;56:1395-1399.

16. Mennella JA, Beauchamp GK. Optimizing oral medications for children. Clin Ther. 2008;30:2120-2132.

17. van Riet-Nales DA, Schobben AF, Egberts TC, Rademaker CM. Effects of the pharmaceutical technologic aspects of oral pediatric drugs on patient-related outcomes: a systematic literature review. Clin Ther. 2010;32:924-938.
18. Szojda MM, Mulder CJ, Felt-Bersma RJ. Differences in taste between two polyethylene glycol preparations. $J$ Gastrointestin Liver Dis. 2007;16:379-381.

19. Couturier D. Comparative study of Forlax and Transipeg in the treatment of functional constipation in the adult. Ann Gastroenterol Hepatol (Paris). 1996;32:135-140. French.

20. Safder S, Demintieva Y, Rewalt M, Elitsur Y. Stool consistency and stool frequency are excellent clinical markers for adequate colon preparation after polyethylene glycol 3350 cleansing protocol: a prospective clinical study in children. Gastrointest Endosc. 2008;68:1131-1135.

21. Seinela L, Sairanen U, Laine T, Kurl S, Pettersson T, Happonen P. Comparison of polyethylene glycol with and without electrolytes in the treatment of constipation in elderly institutionalized patients: a randomized, double-blind, parallel-group study. Drugs Aging. 2009;26:703-713.

22. Gomes PB, Duarte MA, de Melo MC. Comparison of the effectiveness of polyethylene glycol 4000 without electrolytes and magnesium hydroxide in the treatment of chronic functional constipation in children. J Pediatr (Rio J). 2011;87:24-28.

23. Kennedy O, Law C, Methven L, Mottram D, Gosney M. Investigating age-related changes in taste and affects on sensory perceptions of oral nutritional supplements. Age Ageing. 2010;39:733-738.
Patient Preference and Adherence

\section{Publish your work in this journal}

Patient Preference and Adherence is an international, peer-reviewed, open access journal focusing on the growing importance of patient preference and adherence throughout the therapeutic continuum. Patient satisfaction, acceptability, quality of life, compliance, persistence and their role in developing new therapeutic modalities and compounds to

\section{Dovepress}

optimize clinical outcomes for existing disease states are major areas of interest. This journal has been accepted for indexing on PubMed Central. The manuscript management system is completely online and includes a very quick and fair peer-review system. Visit http://www.dovepress.com/ testimonials.php to read real quotes from published authors. 